\title{
Editorial
}

\section{Editorial: CALL Continues to Evolve}

\author{
Nicole Schmidt \\ Managing Editor, ITET
}

\begin{abstract}
Language is a foundational aspect of educational technology. Computer Assisted Language Learning (CALL), has coalesced educational technology trends with advancing theories in language pedagogy; to this day, CALL remains a vital interdisciplinary field, looking at general trends in technology and communication, language learning, and language teaching. Exactly how digital learning affects cultural meaning making processes is still up for debate. We invite you to contribute to that debate through new research and your writing and reviewing for ITET.
\end{abstract}

Keywords: CALL; instructional technology; L2; pedagogical frameworks

Technology has penetrated our daily lives so profoundly that it is difficult to parse from nearly any method of communication. Whether we are aware of it or not, digital media influences personal expression, as it requires competence of vast multimodal social cues to achieve a successful exchange of ideas. This becomes even more complex for language learners, who must use language and technology simultaneously in various cultural contexts (Chun et al., 2016). To come to grips with cultural and digital diversity, they must develop a critical awareness of the "culturally encoded connections among forms, contexts, meanings, and ideologies in a variety of material mediums" (p.66). In other words, they learn to operate in both physical and symbolic, intercultural and multilingual spaces.

One main goal of language teachers who support the digital literacy of their students, then, is to provide opportunities for them to navigate what Chun et al. (2016) refer to as embodied and disembodied language use. Learning to shapeshift between real and virtual environments has long been an aim of Computer Assisted Language Learning (CALL), which began in the 1980s as simple drill and practice exercises, and gradually coalesced educational technology trends with advancing theories in language pedagogy. This resulted in new tools for exploratory language learning, such as concordance software, cloze programs, and office programs like desktop publishing software, email, and spread sheets. Such software provoked the first shift away from grammar towards 
narrative, interactive, and game-based platforms. By the late 1990s, developments in technology delivered us from the discovery of the internet to the birth of social networking. Around that time, "e-learning" became a buzzword, learner management systems like Blackboard were created, and CALL became a burgeoning research area which fused language education and integrative technology. Even during these early days, students were taught that communicative competence can transcend physical environments.

With the turn of the century, language learning became increasingly versatile. CALL and Web 2.0 in the early 2000s witnessed the advent of complete online language courses, and "blended learning" replaced "e-learning" in full recognition of the social aspect in language learning (Davies et al., 2013). New wideband capabilities reinforced the proliferation of social networks, and the increased use of handheld mobile devices in the early 2010s further solidified these trends (Torsani, 2016). This new age of blended learning ushered constructivist pedagogies with tools like discussion forums, blogs, Wiki's, and podcasts, to name a few. Digital media had become a collaborative space promoting "output-oriented language learning scenarios with a focus on stimulating meaning negotiation and output production more practical at the grassroots level" (Davies et al., 2013, p. 33). You could interact with people from all around the world in both synchronous and asynchronous disembodied states.

To this day, CALL remains a vital interdisciplinary field, looking at general trends in technology and communication, language learning, and language teaching. To address challenges related to language use in rapidly fluctuating digital environments, research in the adjacent field of CMC (Computer Mediated Communication) branched into three directions: (1) investigation of digital learning environments; (2) analysis of the social/ affective components that mediate online communication; and (3) the effectiveness of different instructional processes matching linguistic activities with various technological tools (Torsani, 2016). CMC informs several L2 pedagogical frameworks (e.g., functional, awareness raising, and new literacies) for developing digital L2 literacy (Reinhardt \& Thorne, 2011). Another branch of CALL research investigates building both teacher and learner confidence to adopt new technologies in the classroom (Hubbard, 2013; Kessler \& Plakans, 2008; Røkenes \& Krumsvik, 2016).

CALL has seen immense changes in the past few decades, and it continues to evolve, along with the broader scholarship of language education and educational technology. While there are multiple approaches to investigating technology and language learning, most experts agree that it involves some combination of contextualized language use, language awareness, and cultural understanding. Reinhardt and Thorne state that, in addition to practicing language and monitoring its structure, learners should appreciate culture as "a set of meaningful practices, and that some participation in and through those practices is necessary to truly learn about [language] as a system of meaning making" (2011, p. 16). Exactly how digital learning affects cultural meaning making processes is still up for debate. 
We at ITET invite you to contribute to that debate. We receive many submissions from language scholars and are always looking for new research which melds the fields of language education and educational technology. We also invite volunteers to review submissions specific to language learning technologies to further strengthen our learning community. Language is a foundational aspect of educational technology. Without it, there will be no final ' $\mathrm{C}$ ' in $\mathrm{CMC}$. We look forward to your continued communication with ITET.

\section{References}

Chun, D., Kern, R., \& Smith, B. (2016). Technology in language use, language teaching, and language learning. The Modern Language Journal, 100(S1), 64-80.

Davies, G., Otto, S., \& Ruschoff, B. (2013). Historical perspectives on CALL. In M. Thomas, H. Reinders, \& M. Warschauer (Eds.), Contemporary computer-assisted language learning (pp. 19-39). New York, NY: Bloomsbury Academic.

Hubbard, P. (2013). Making a case for learner training in technology enhanced language learning environments. Calico Journal, 30(2), 163-178.

Kessler, G., \& Plakans, L. (2008). Does teachers' confidence with CALL equal innovative and integrated use?. Computer Assisted Language Learning, 21 (3), 269-282.

Reinhardt, J., \& Thorne, S. (2011). Beyond comparisons: Frameworks for developing digital L2 literacies. In Present and future promises of CALL: From theory and research to new directions in language teaching, 257-280.

Røkenes, F. M., \& Krumsvik, R. J. (2016). Prepared to teach ESL with ICT? A study of digital competence in Norwegian teacher education. Computers \& Education, 97, $1-20$.

Torsani, S. (2016). CALL Teacher Education: Language Teachers and Technology Integration. Springer. 